\title{
Multiscale analysis of factors affecting food security in China, 1980-2017
}

\author{
Furong Lv ${ }^{1}$ (I) $\cdot$ Longyun Deng $^{1} \cdot$ Zhengtao Zhang $^{2} \cdot$ Zheye Wang $^{3} \cdot$ Quanyuan Wu $^{1} \cdot$ Jianmin Qiao ${ }^{1}$
}

Received: 17 May 2021 / Accepted: 19 August 2021 / Published online: 28 August 2021

(C) The Author(s), under exclusive licence to Springer-Verlag GmbH Germany, part of Springer Nature 2021

\begin{abstract}
Food security is an important issue affecting people's lives and social stability. Clarifying levels of food security and the factors affecting it (social, economic, agricultural, climatic) can help improve regional food security. The spatiotemporal patterns and driving factors of food security vary at different scales. There is, however, a lack of research that considers the various factors affecting food security at multiple scales. This study, therefore, analyzed dynamic spatiotemporal changes in food security at small (city), medium (province), and large (country) scales; identified hot and cold areas of food security; and revealed the main factors affecting food security at different scales. A food security index (FSI) was built based on the coupling of grain yield, population, and GDP, and spatial analysis was used to evaluate dynamic spatiotemporal changes in China's food security from 1980 to 2017. Further, the relationship between food security and its driving factors was quantitatively analyzed using stepwise regression. The results showed greater heterogeneity in food security at the smaller scale than at the larger scale. The key factors affecting food security varied substantially at different scales: the added value of tertiary industry dominated the prefecture level, and gross agricultural output value was the main factor at the provincial and national levels. Multiple-scale research can reveal the status and primary factors of food security and provide a decision-making basis for improving regional food security.
\end{abstract}

Keywords Food security index $\cdot$ Driving factors $\cdot$ Spatiotemporal pattern $\cdot$ Multiple scales

\section{Introduction}

Food security is closely related to people's well-being. It is also an important guarantee for a country's economic development as well as a strategic issue related to national peace and stability (Merem et al. 2019; Mukhopadhyay et al. 2018).

Responsible Editor: Philippe Garrigues

Quanyuan $\mathrm{Wu}$

wqy6420582@163.com

Jianmin Qiao

qjmwilson@sdnu.edu.cn

1 School of Geography and Environment, Shandong Normal University, No. 88 WenHuaDong Road, Jinan 250014, Shandong, China

2 Academy of Disaster Reduction and Emergency Management Ministry of Civil Affairs\& Ministry of Education, Beijing Normal University, Beijing 100101, China

3 Department of Environmental Sciences, College of the Coast and Environment, Louisiana State University, Baton Rouge, LA 70803, USA
Food security "exists when all people, at all times, have physical, social, and economic access to sufficient, safe, and nutritious food that meets their dietary needs and food preferences for an active and healthy life" (FAO 1996). High levels of food insecurity and hunger will lead to major public health issues, including increases in infectious diseases and premature deaths (Qaim 2020). For its 2030 Sustainable Development Goals, the United Nations has ranked "ending hunger, achieving food security, improving nutrition, and promoting sustainable agriculture" second among 17 goals, highlighting the importance of food security (UN 2015). Yet, after decades of decline, the number of hungry people in the world has begun to rise in recent years (Molotoks et al. 2021), which will likely make the UN's goal difficult to achieve by 2030. In fact, the COVID-19 pandemic has further exacerbated world hunger (Laborde et al. 2020; Zurayk 2020). Thus, food security will remain a global priority for decades to come (Conceição et al. 2016; Sisha 2020) and a prerequisite for other Millennium Development Goals (Cai et al. 2020).

In the face of such food security problems, only by accurate assessment of food security and identification of food security risk areas can policy optimization measures be formulated. 
Many studies have investigated evaluation methods for food security at various scales and from different perspectives (Barrett 2010; Godfray et al. 2010; Pinstrup-Andersen 2009). At the global scale, the Global Hunger Index (GHI) was developed to measure changes in the number of hungry people in different regions of the world (Grebmer et al. 2012). Meanwhile, at the continental scale, Li and Zhang (2017) used dietary energy requirements, local food production, and population size to calculate the number of undernourished people in Africa and identify dynamic changes in risk areas and their spatial distribution. At the national scale, Ye et al. (2013) evaluated China's food security under different climate scenarios and at different times using a food security index based on food supply, demand, and self-sufficiency. Despite such work, there is regional heterogeneity in food security, and current methods are not fine-grained enough to provide detailed decision-making information or offer an understanding of the scale effect of food security. Moreover, food security results from the combined action of multiple factors. Although investigating food security from a single perspective, such as climate, agriculture, or socioeconomics, can deepen the understanding of food security influence factors (Andersson Djurfeldt 2015; Kang et al. 2017; Lake et al. 2012; Masters et al. 2013; Qaim 2020), multifactor approaches can better clarify and disentangle them. However, multi-scale studies considering multiple influencing factors are scarce.

Food security has long been an important topic in China, the world's most populous country (Liu et al. 2020a; Tao et al. 2008). Since 1987, China's population has grown rapidly from 0.99 billion in 1980 to 1.39 billion in 2017 and with the relaxing of the two-child policy, the population may grow even faster (Liu et al. 2020b), bringing more serious challenges to food security. On this context, numerous studies have been done on China's food security assessment from the point of food supply and demand (Qi et al. 2015), production-consumption coordination (Wu et al. 2016), food self-sufficiency (Niu et al. 2021), and food policy (Huang and Yang 2017). China's food security generally showed an increasing trend before 2010 and then it started to decline as a result of rapid population growth and nonoptimal socioeconomic and agricultural development (Ye et al. 2013). From the perspective of food production-consumption coordination and matching, although the coordination level in China remained high during 1995 to 2012, it started to decrease continuously since 2007 (Wu et al. 2016).

Although China has achieved food security at the national level, scale differences and spatial heterogeneity in food security and its influencing factors are existed. There are regional differences in food output, economic development, and population size, among other aspects. To address such challenges and take appropriate measures, it is necessary to precisely assess food security, identify risk areas, and quantify the main driving factors. To solve the abovementioned problems, this study investigated the dynamic changes and driving factors of China's food security at the national, provincial, and prefectural scales. The objectives are to (1) accurately assess the spatial and temporal dynamics of food security at the three scales with the developed food security index (FSI), (2) analyze the trend changes in food security from 1980 to 2017, and (3) identify the hotspot and cold spot of food security and clarify the dominant factors.

\section{Data and methods}

\section{Study area and data acquisition}

This study covered three scales: (1) national scale: mainland China; (2) provincial scale: 23 provinces, fives autonomous regions, and four direct-administered municipalities; and (3) prefecture-level scale: 291 cities, 15 regions, 30 autonomous prefectures, and three leagues (Fig. 1).

The data included meteorological data (site data) and statistical data. Meteorological data, including temperature and precipitation, were obtained for the period of 1980-2017 from the National Meteorological Information Center of the China Meteorological Administration. Kriging interpolation (a Gaussian semivariance model) and ArcGIS (10.6) were used to obtain the average annual temperature and precipitation of each city and province. Statistical data for each province and city, covering 1980-2017, came from the statistical yearbooks and included the following: the degree of urbanization, grainplanting area, cultivated land area, total power of agricultural machinery, amount of fertilizer application, effective irrigation area, population, grain output, gross domestic product (GDP), and added value of primary, secondary, and tertiary industry (Table 1).

\section{Assessment of food security}

The level of food security results from the combined action of many factors (Cai et al. 2020); thus, a single perspective cannot accurately reflect it (Wei et al. 2015). Based on the definition of food security by FAO, this study built a FSI from four dimensions of availability, stability, utilization, and access, and took per-capita food production and per-capita GDP as the key indicators to characterize the food security situation. The per-capita GDP was used to represent the situation of food affordability and accessibility, and the per-capita food production was used to reflect the status of stability and availability (Fig. 2). It was assumed that the higher a region's percapita food production and per-capita GDP, the higher its level of food security (GDP can be converted into food purchasing power to make up for the lack of local food production), and vice versa. It should be noted that food security in this study 
Legend
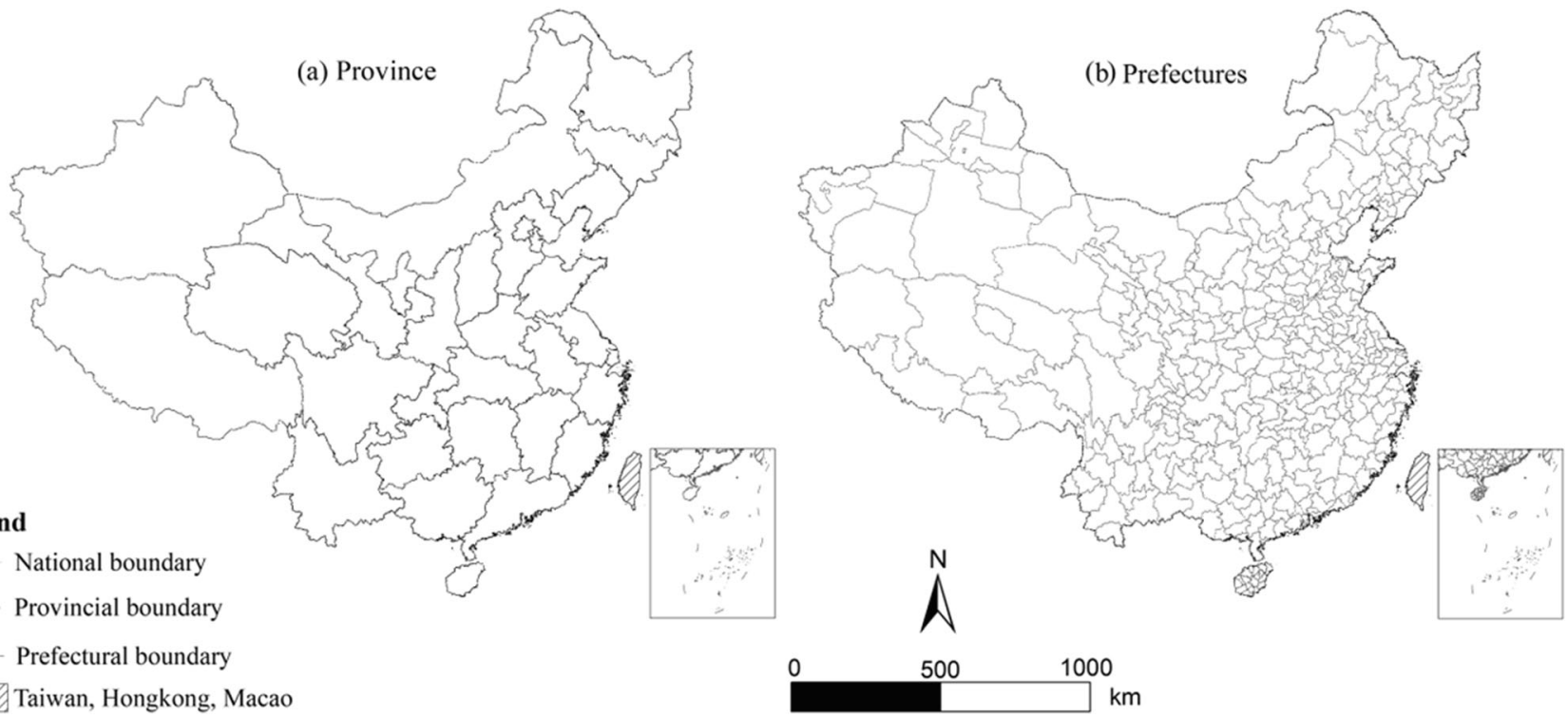

Fig. 1 Maps of the study area, mainland China, showing three administrative levels: country, provinces (a), prefectures (b)

represents relative rather than absolute food security. Food security was divided into five levels (Table 2): extremely low security (ELS) $(0 \leq \mathrm{FSI}<0.5)$, low security (LS) $(0.5 \leq$ FSI $<1)$, security (S) $(1 \leq \mathrm{FSI}<1.5)$, medium security (MS) $(1.5 \leq$ FSI $<2)$, and high security (HS) $(2 \leq$ FSI). FSI can quantitatively evaluate the food security of a region relative to the global average. With reference Wu et al. (2011), FSI was built as follows:

$F S I_{t, n}=\left(\frac{P G D P_{n, t}}{P G D P_{g, t}}+\frac{P F O O D_{n, t}}{P F O O D_{g, t}}\right) * 0.5$

where $\mathrm{FSI}_{t, n}$ is the FSI of region $n$ at time $t ; \mathrm{PGDP}_{n, t}$ is the per- capita GDP of region $n$ at time $t ; \operatorname{PFOOD}_{n, t}$ is the per-capita grain output of region $n$ at time $t \operatorname{PGDP}_{g, t}$ is the per-capita global GDP at time $t ; \mathrm{PFOOD}_{g, t}$ stands for per-capita global food production at time $t$.

\section{Getis-Ord Gi*}

Getis-Ord Gi* is commonly used to analyze the clustering characteristics and identify spatial clustering of hot and cold spots with statistical significance. To be a statistically significant hotspot (cold spot), the area should have a high value (low value) and be surrounded by other areas that also have
Table 1 Description of the data used in this study

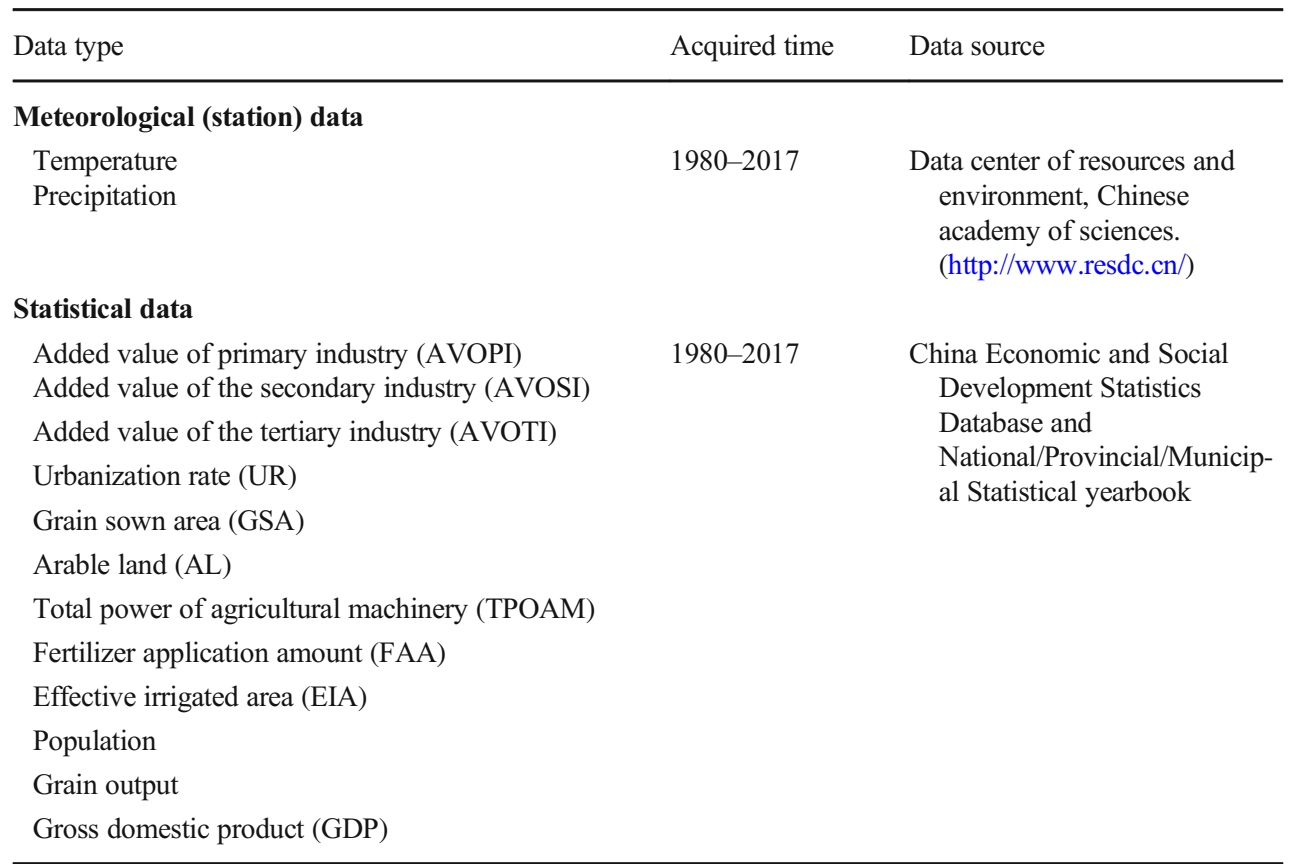


Table 2 Classification of food security level.

\begin{tabular}{llllll}
\hline Security levels & $\begin{array}{l}\text { Extremely low } \\
\text { security }\end{array}$ & $\begin{array}{l}\text { Low } \\
\text { security }\end{array}$ & Security & $\begin{array}{l}\text { Medium } \\
\text { security }\end{array}$ & $\begin{array}{l}\text { Highly } \\
\text { security }\end{array}$ \\
\hline $\begin{array}{l}\text { Food security } \\
\text { index }\end{array}$ & $0-0.5$ & $0.51-1$ & $1.01-1.5$ & $1.51-2$ & $>2$ \\
\hline
\end{tabular}

high (low) values. If the factor has a high $z$-score and a small $p$-value, there is high-value spatial clustering. If the $z$-score is low and negative, and the $p$-value is small, there is a spatial cluster with a low value. The higher (lower) the $z$-score, the greater (smaller) the degree of clustering. If the $z$-score is close to zero, there is no obvious spatial clustering (Mondal 2020). The Gi* index can be used to identify hot and cold spots of food security and analyze their dynamic spatiotemporal changes. Getis-Ord Gi* is calculated as follows:

$G_{i}^{*}=\frac{\sum_{j=1}^{n} w_{i, j} x_{j}-\bar{X} \sum_{j=1}^{n} w_{i, j}}{\sqrt[s\left[n \sum_{j=1}^{n} w_{i, j}^{2}-\left(\sum_{j=1}^{n} w_{i, j}\right)^{2}\right]]{n-1}}$

$\bar{X}=\frac{\sum_{j=1}^{n} x_{j}}{n}$

$S=\sqrt{\frac{\sum_{j=1}^{n} x_{j}^{2}}{n}-(\bar{X})^{2}}$

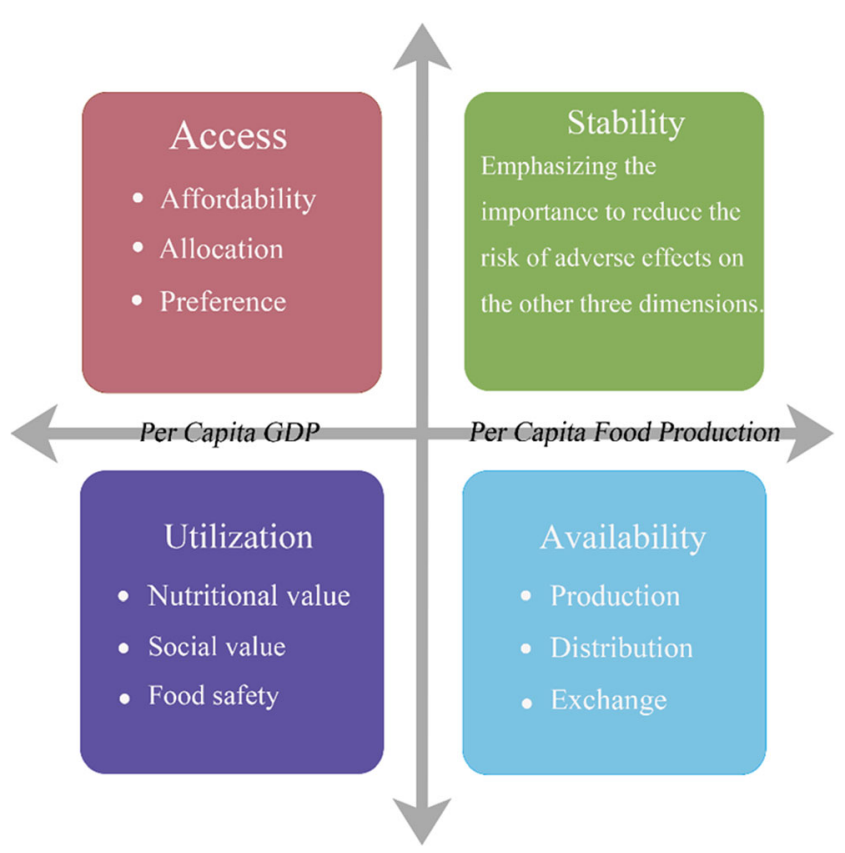

Fig. 2 Four dimensions of food security with their main meanings where $x_{j}$ is the attribute value of factor $j, W_{i, j}$ is the spatial weight between factors $i$ and $j$, and $G_{i}^{*}$ represents the $z$-score.

\section{Stepwise multiple linear regression}

In this study, correlation analysis was used to eliminate nonsignificant correlation factors, and then converted multiple driving factors into a few comprehensive indicators based on dimensionality reduction through principal component analysis to represent most of the information of multiple driving factor variables. According to the contribution degree of different factors to the principal component, the unimportant independent variables were deleted to reduce the duplicated information. Finally, multiple stepwise regression analysis was used to quantify the impact of each driving factor on food security, so as to eliminate the impact of multicollinearity on the research results.

This study selected agricultural factors closely related to food security: grain-sown area (GSA) (Chen et al. 2011), arable land area (AL) (Wei et al. 2017), total power of agricultural machinery (TPOAM) (Mukhopadhyay et al. 2018; Qi et al. 2015), fertilizer application amount (FAA) (Wang et al. 2018b), and effective irrigation area (EIA) ( $\mathrm{Li}$ and Singh 2019). Climate factors (temperature and precipitation) (Leisner 2020; Zurayk 2020) and socioeconomic factors (added value of primary, secondary, and tertiary industry (AVOPI, AVOSI, AVOTI) and degree of urbanization (UR)) (Chen 2007) were used to identify the leading factors affecting food security. The function relationship between driving factors and food security can be expressed by the following:

$$
\begin{aligned}
\mathrm{FSI}= & k_{1} x_{1, t}+k_{2} x_{2, t}+k_{3} x_{3, t}+k_{4} x_{4, t}+k_{5} x_{5, t}+k_{6} x_{6, t} \\
& +k_{7} x_{7, t}+k_{8} x_{8, t}+k_{9} x_{9, t}+k_{10} x_{10, t}+k_{11} x_{11, t}
\end{aligned}
$$

where FSI is the normalized food security index in period $t ; \mathrm{x}_{1}$, ..., $\mathrm{x}_{11}$ AVOPI, AVOSI, AVOTI, UR, GSA, AL, TPOAM, FAA, EIA, and average temperature and precipitation; $k_{1}, \ldots$, $k_{11}$ is the regression coefficient of each driving factor. The normalized regression coefficient can reflect the relationship between driving factors and food security, and the influence degree of driving factors. All statistical analyses were performed using IBM SPSS Statistics 24. 


\section{Results}

\section{Spatiotemporal patterns of food security}

FSI was used to quantitatively evaluate spatiotemporal patterns of food security in China from 1980 to 2017 at the prefectural, provincial, and national scales. The results showed that food security exhibited obvious spatial heterogeneity, and varied with scales. Overall, during the past three decades, China's food security has dramatically improved, while many regions were still below the global average level in 2017.

\section{Food security at prefectural scale}

At prefectural scale, the spatiotemporal pattern of food security changed significantly during 1980-2017. The number of cities below the global average food security (levels ELS and LS) decreased by $39 \%$ from 324 to 198, and the number of cities in food-secure zones (levels S, MS, and HS) increased by 18 times, indicating a significant improvement in food security (Fig. 3(f)). In terms of spatial distribution patterns, the food security levels of most cities were ELS $(50 \%)$ or LS (48\%), with a few at HS in 1980. Spatial heterogeneity in food security was small. By 2017, although most cities were still below the global average level of food security $(60 \%)$, they were primarily at level LS (52\%). The proportion of ELS level cities (8\%) decreased significantly; these were mainly distributed in Tibet and Qinghai Province in Southwest and Northwest China, respectively (Fig. 3). These cities (9.1\%) that exhibited downward trend were mainly distributed in Guangdong (9), Sichuan (4), and Zhejiang (7) Provinces, among which Wenzhou in Zhejiang Province showed the fastest downward trend $\left(-0.09\right.$ year $\left.^{-1} ; p<0.01\right)$. By contrast, cities in Northeast China, western Inner Mongolia, and northern Xinjiang saw rapid improvements in food security, with Suihua in Heilongjiang Province showing the fastest growth $\left(0.14\right.$ year $\left.^{-1} ; p<0.01\right)$ (Fig. 4(a)).

During the study period, there were significant spatial differences in the distribution of food-security cold spots and hotspots. In 1980, hotspots were concentrated in northeastern and southeastern coastal cities while cold spots were concentrated in middle-north and southwestern cities (Fig. 5(a)). Over time, the cold spots in the middle north shifted toward the southwest, and the hotspots in the southeastern coastal regions decreased. By 2000, food-security hotspots in the southeastern coastal areas disappeared, and new hotspots appeared in Shandong Province (Fig. 5(c)). Compared with 2000, food-security hotspots had no noticeable change in 2010, but the range of cold spots had expanded significantly, mostly concentrated in Southwest China (Fig. 5(d)). In 2017, there was no significant change in the range of hotspots in Northeast China while the number of hotspots in northern Xinjiang increased significantly (Fig. 5(e)). Overall, from
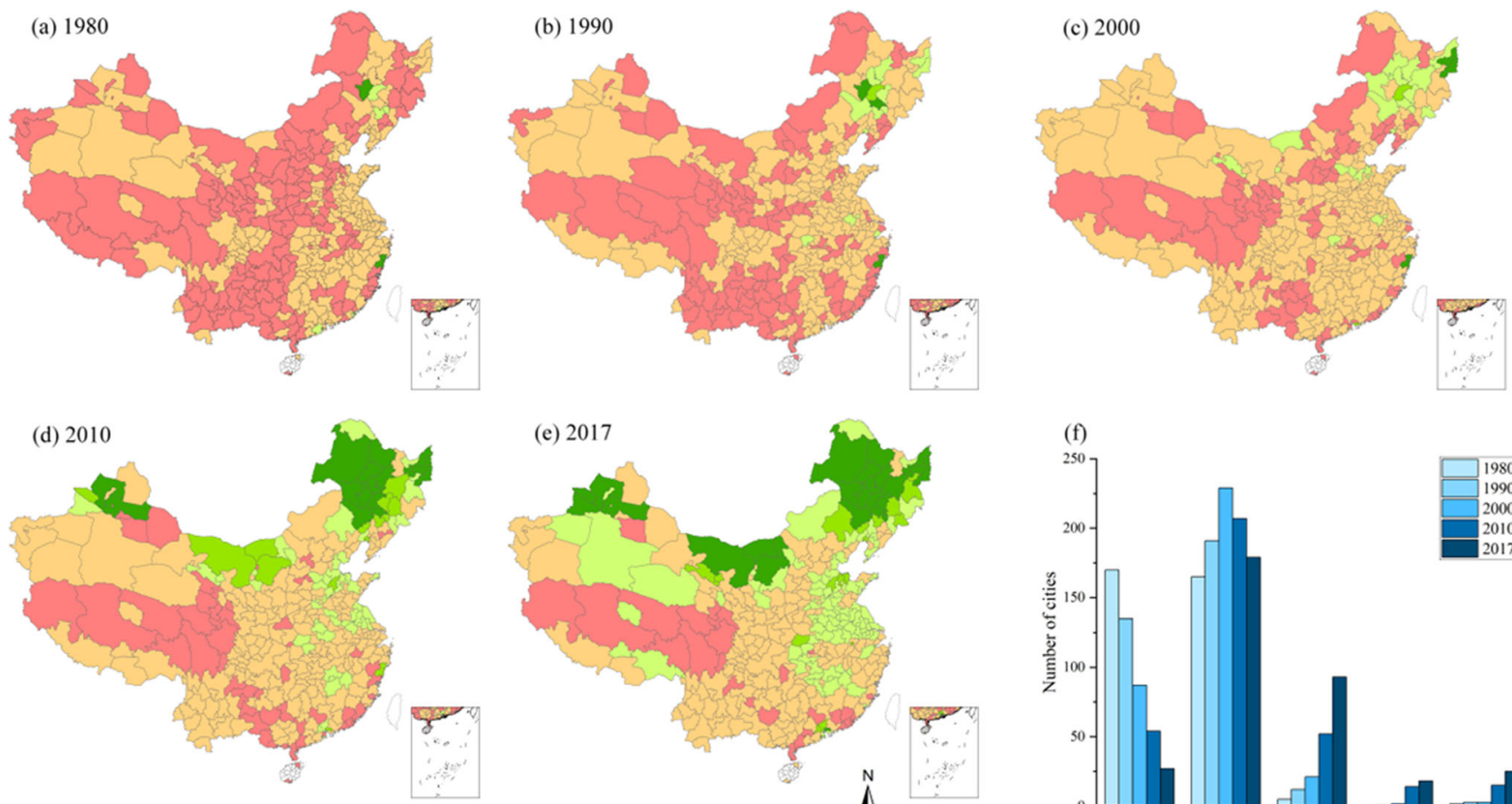

(e) 2017

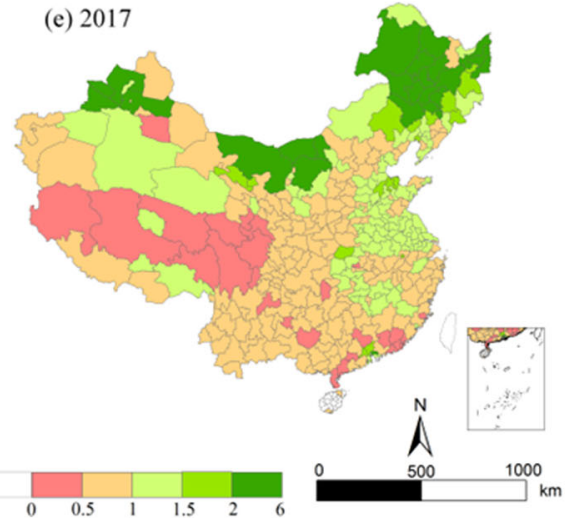

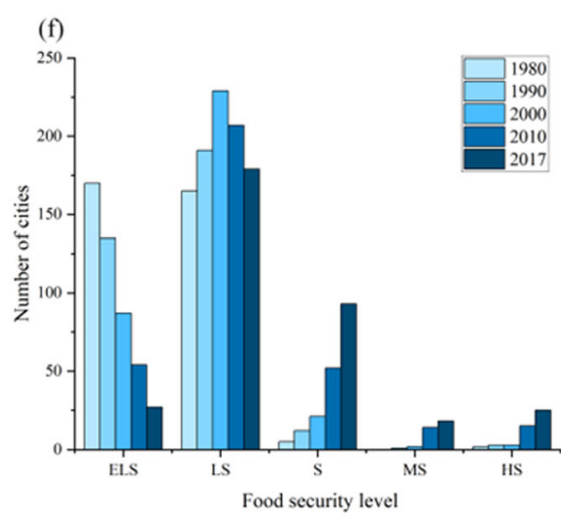

Fig. 3 Spatial patterns of food security at prefectural scale from 1980 to 2017. Notes: Please refer to Table 2 for the full names of food security level 
(a) Prefecture

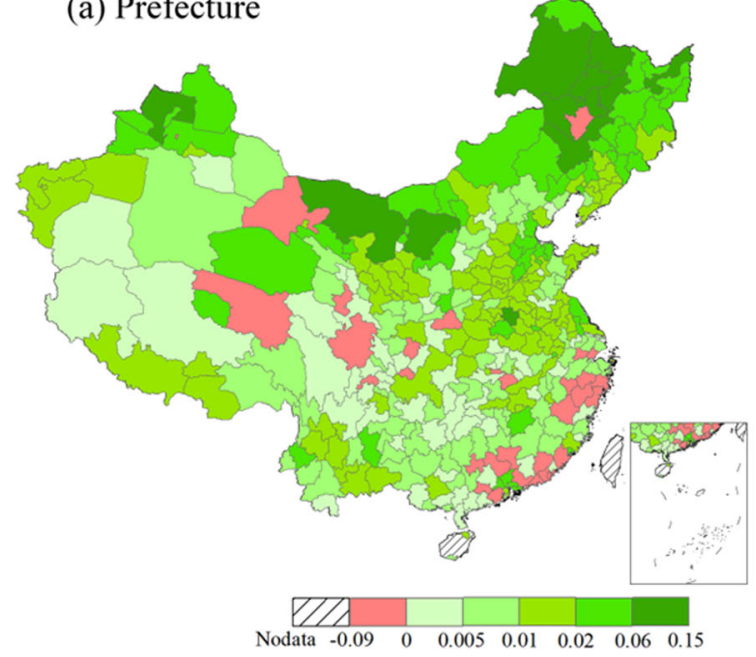

(b) Province

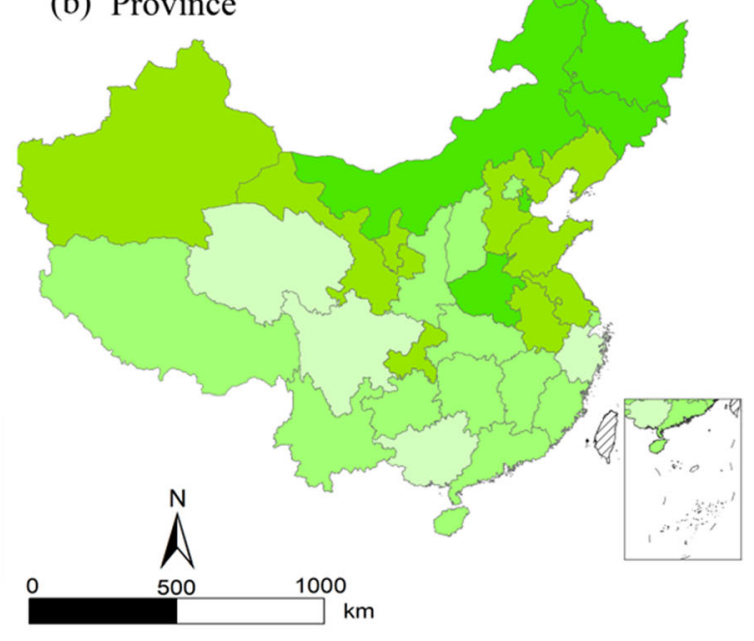

Fig. 4 Linear trend changes in food security state at prefectural (a) and provincial (b) scales during 1980-2017

1980 to 2017, the range of cold spots increased significantly, mainly in Southwest China. In terms of hotspots, the spatial distribution pattern obviously changed, except in Northeast China.

\section{Food security at the provincial scale}

At the provincial level, the number of provinces in a state of S increased by 32\% from 1980 to 2017 (Fig. 6(f)). The fastest growth rate was in Heilongjiang Province (0.06 year ${ }^{-1} ; p<0.01$ ), followed by Inner Mongolia, Jilin, Tianjin, and Henan, and Zhejiang had the slowest growth rate (Fig. 4(b)). Although other provinces were still below the global average level of food security by the end of the research period, the level of food security improved significantly (Fig. 6). Hotspot analysis showed that, at the 95\% confidence level, the spatial pattern of foodsecurity hotspots had no obvious change from 1980 to
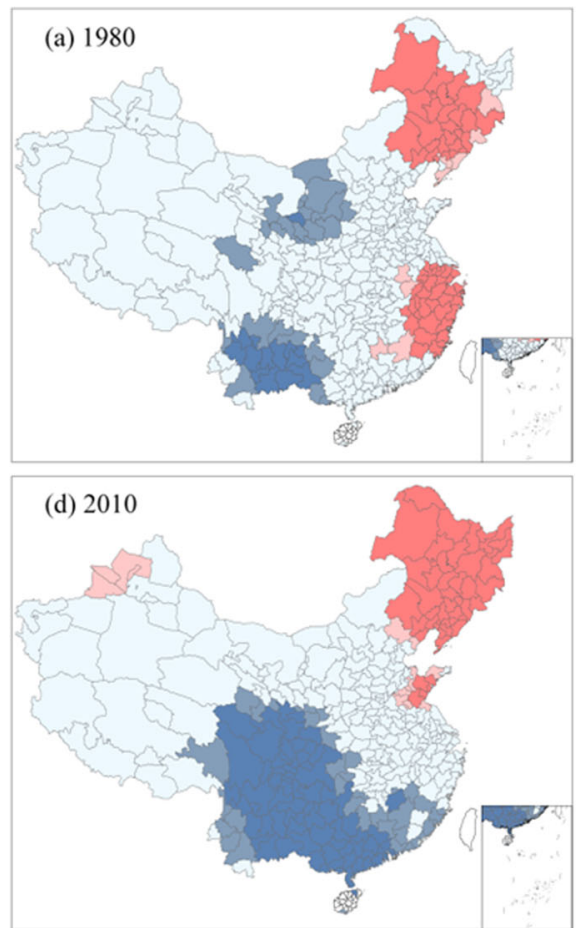

(b) 1990

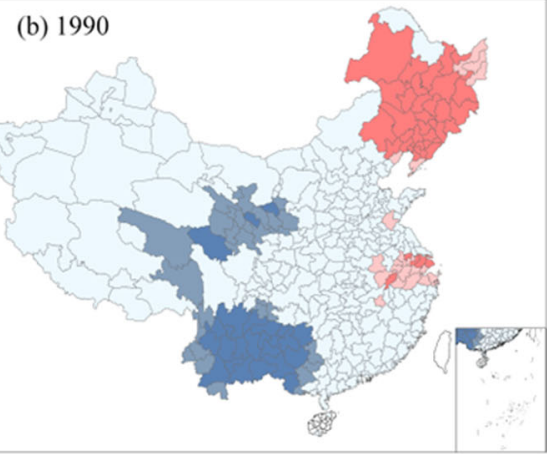

(e) 2017

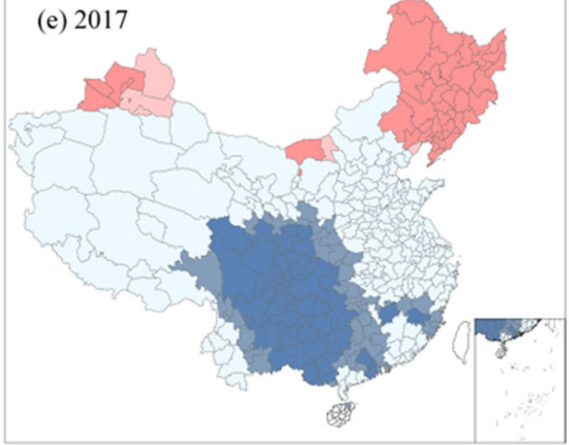

(c) 2000
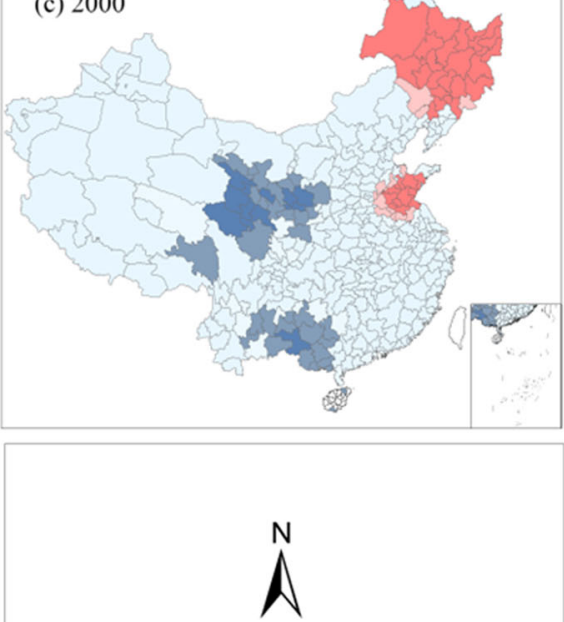

0

Cold hot spots with different confidence

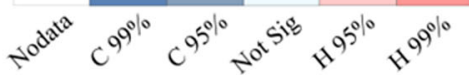

Fig. 5 Hot and cold spots of food security at prefectural scale from 1980 to 2017 

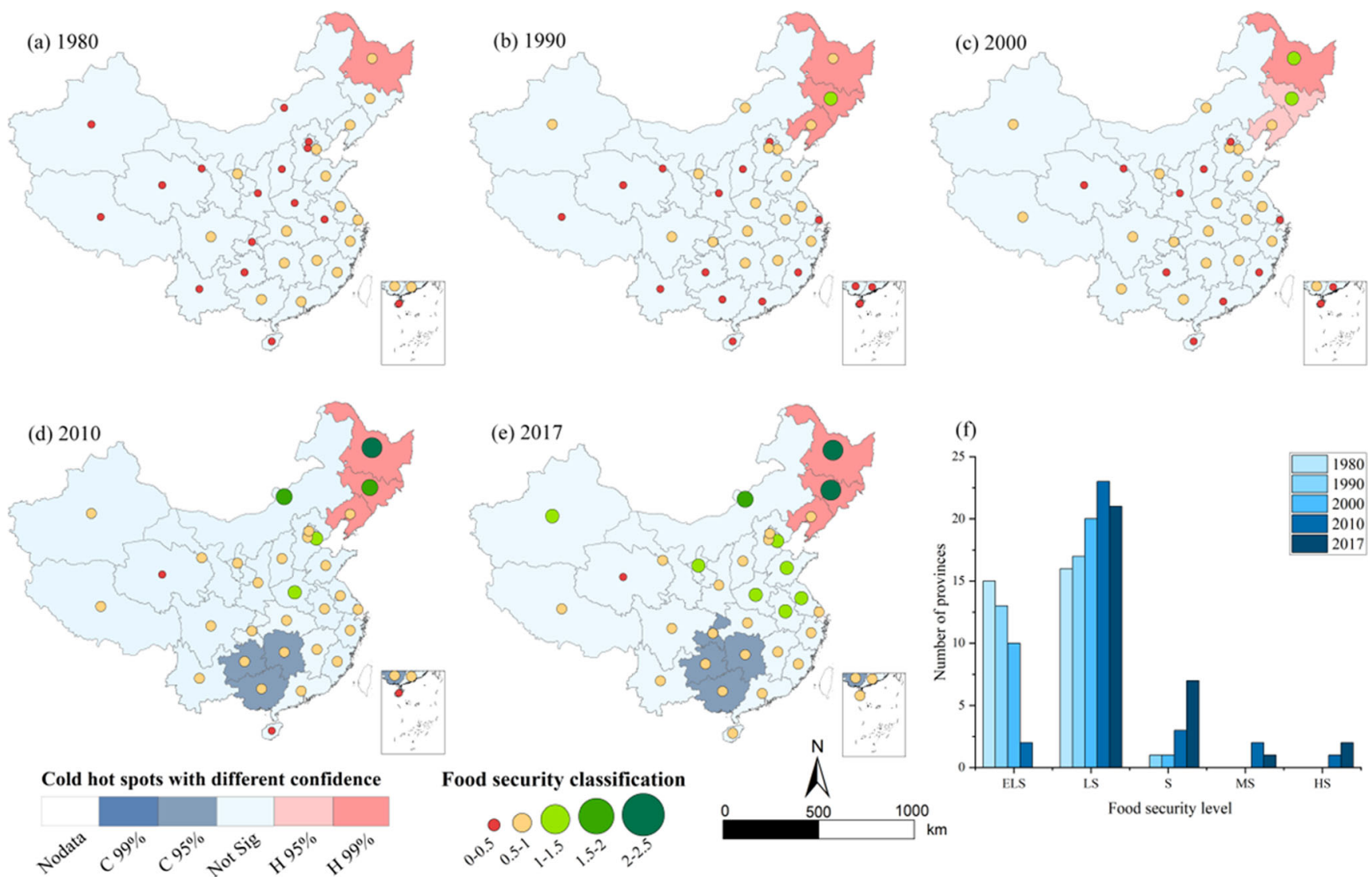

Fig. 6 Spatial patterns and hot and cold spots of food security at provincial scale, 1980-2017. Notes: Please refer to Table 2 for the full names of the food security level

2017, and all were concentrated in Northeast China. From 1980 to 2000 , there were no food-security cold spots. In 2010, food-security cold spots appeared mainly in Guangxi, Guizhou, and Hunan Provinces in southern China. In general, food-security cold spots and hotspots gradually formed a stable spatial distribution pattern from 1980 to 2017, with stable hotspots forming in Northeast China and stable cold spots forming in Southwest China (Fig. 6).

\section{Food security at the national scale}

At the national level, China's food security was low compared with the global average. From 1980 to 2014, food security of China was below the global average. Nevertheless, China's overall food security exhibited an upward trend, with an average annual growth rate of $1.8 \%$. During 1980 to 2005 , food security changed slightly, fluctuating around 0.6. By 2015, China reached the global average level, and the FSI exceeded 1. Overall, FSI increased from 0.51 in 1980 to 1.02 in 2017 $\left(0.01\right.$ year $\left.^{-1} ; p<0.01\right)$ (Fig. 7).

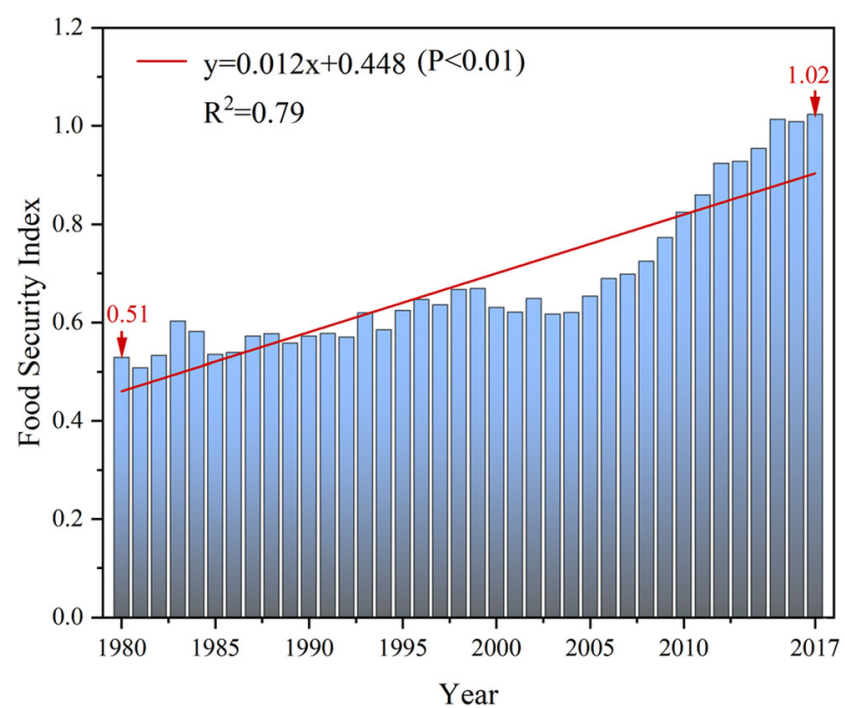

Fig. 7 Variation in food security index at national scale from 1980 to 2017 


\section{Driving factors of food-security changes at various scales}

\section{Driving factors of food-security changes at the prefectural scale}

Multiple regression analysis showed obvious spatial heterogeneity in the main factors affecting food security, and the relationship between food security and its influencing factors also changed with scale (Fig. 8). The agricultural factors FAA and TPOAM and the economic factors AVOPI, AVOSI, and AVOTI had positive effects on food-security changes at the prefectural scale. For $89 \%$ of cities, the agricultural factors $\mathrm{AL}$ and GSA and the social factor of UR had positive effects on food security while for $11 \%$ of cities, they had negative effects (Fig. 9). Among economic factors, about 20\% of urban food security was affected by AVOTI, with standardized regression coefficients ranging from 0.74 to 1.2 . Next, $19 \%$ of prefecture-level food-security changes were mainly affected by AVOPI. Among agricultural factors, food security for $13 \%$ of prefecture-level cities were mainly affected by FAA. In general, economic factors, especially AVOTI, were the dominant factors affecting food security at the prefectural scale (Fig. 10).

\section{Driving factors of food-security changes at the provincial scale}

At the provincial level, agricultural factors (FAA, EIA, TPOAM) and economic factors (AVOPI, AVOSI, AVOTI) were the most important factors affecting food security

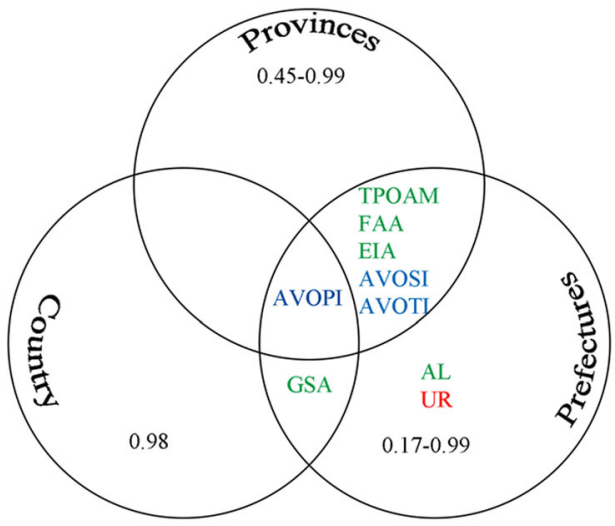

Economic factors

Social factors

Agricultural factors

Fig. 8 Venn diagram of the driving factors for food security at three scales (national, provincial, and prefectural) from 1980 to 2017. Blue, red, and green represent economic, social, and agricultural factors, respectively. Economic factors include AVOPI, AVOSI, and AVOTI; social factors include UR; and agricultural factors include TPOAM, EIA, FAA, AL, and GSA. The number in each circle is the range of adjusted $R^{2}$
(Fig. 8). They had positive effects on food security for each province (Fig. 11). Among economic factors, food security level for $29 \%$ of provinces were mainly affected by AVOPI (standardized regression coefficients: 0.84-1.12). Next, more than $22 \%$ of provinces were mainly affected by AVOTI (standardized regression coefficients: 0.88-1.61). Among agricultural factors, FAA was the most important, playing a leading role in $16 \%$ of provinces (standardized regression coefficients: 0.57 to 1.04 ) (Fig. 12). Overall, for most provinces, AVOPI was the main factor affecting food security; however, AVOTI had a greater effect on food security than AVOPI (Fig. 12; Table 3). During the research period, in more than $80 \%$ of provinces, $90 \%$ of changes in food security were explained by the above factors (Table 3 ).

\section{Driving factors of food-security changes at the national scale}

Economic (AVOPI) and agricultural (GSA) factors were the main factors affecting changes in food security, both with positive effects. Between 1980 and 2017, AVOPI and GSA jointly explained $98 \%$ of the changes in China's food security (Fig. 8). According to the regression coefficients, AVOPI (0.94) had a greater effect on food security than GSA (0.13).

\section{Discussion}

\section{Spatiotemporal patterns of food security}

This study built a food security evaluation index based on grain yield, population, and GDP and used spatial analysis to evaluate dynamic spatiotemporal changes in food security from 1980 to 2017 at multiple scales (prefecture, province, and national levels). Compared with previous studies (Cao et al. 2017; Nath et al. 2015; Qi et al. 2015; Wang 2019), this study more comprehensively considered the dimensions of food security and revealed its multiscale changes and spatial heterogeneity. During the research period, food security in China generally rose at the prefectural, provincial, and national scales.

Different from previous studies on food security at the provincial and national scales, researches at prefectural scale can better reveal spatial heterogeneity and identify risk areas in food security. The spatial distribution pattern indicated that food security increased significantly in Northeast China and northern Xinjiang from 1980 to 2017. For example, during the research period, food security in Suihua, Heilongjiang Province, rose from low security (LS) to high security (HS). The reason for this is that Suihua is located in the Songnen Plain, one of China's most important grain-production bases and a hotspot for increased grain output. This finding is consistent with Yu et al. (2018). The food security of Karamay in Xinjiang was upgraded from extremely low (ELS) to security (S). Per-capita food production in the region increased by 
(a) FAA

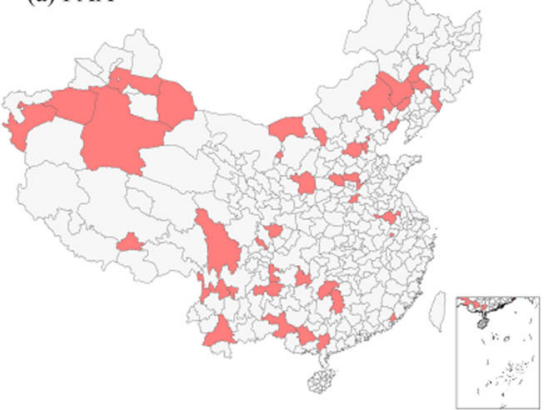

(d) EIA

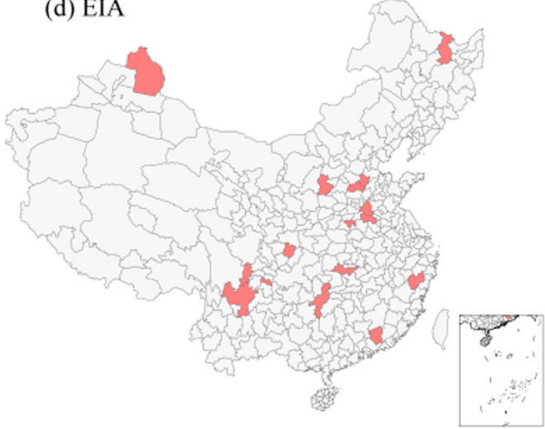

(g) AVOSI

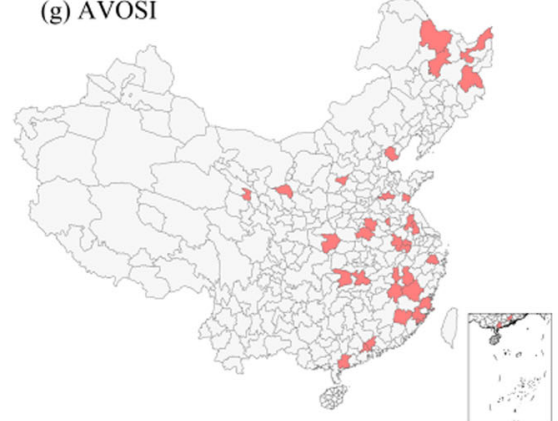

(b) $\mathrm{AL}$

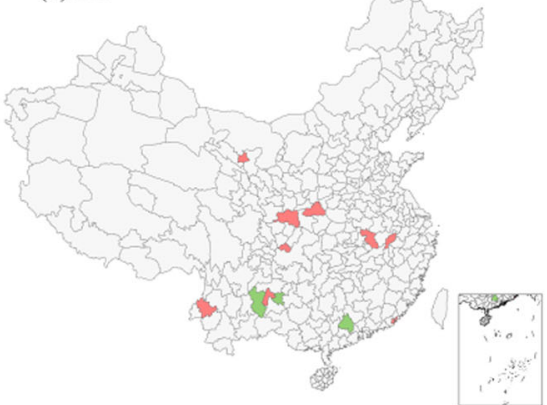

(e) TPOAM

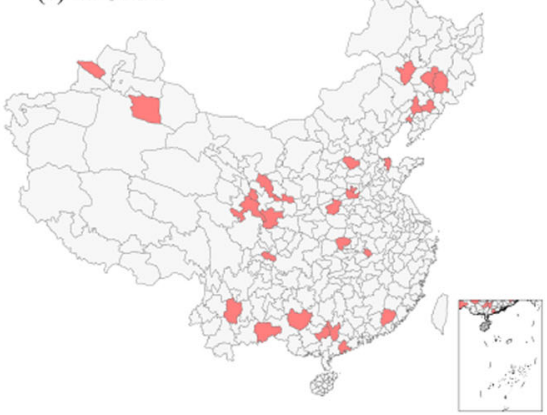

(h) AVOTI

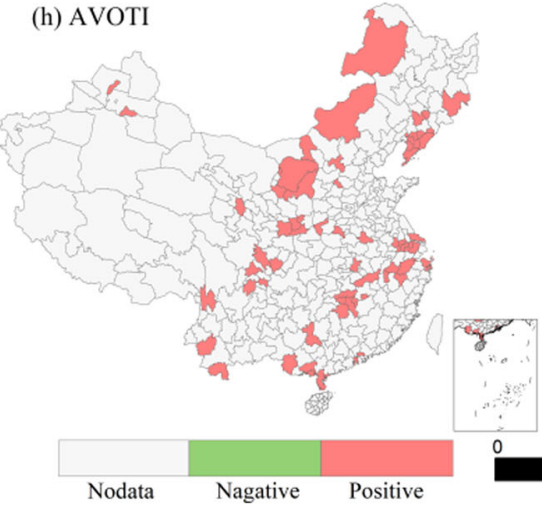

(c) GSA

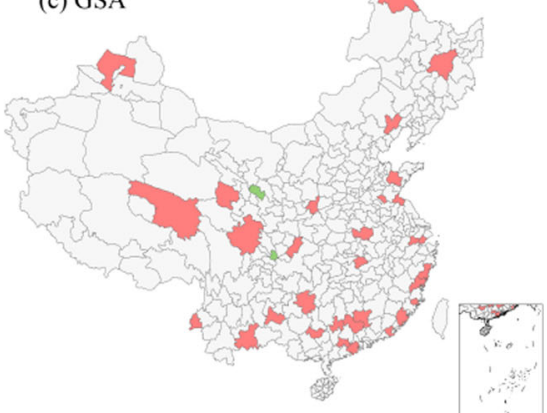

(f) AVOPI

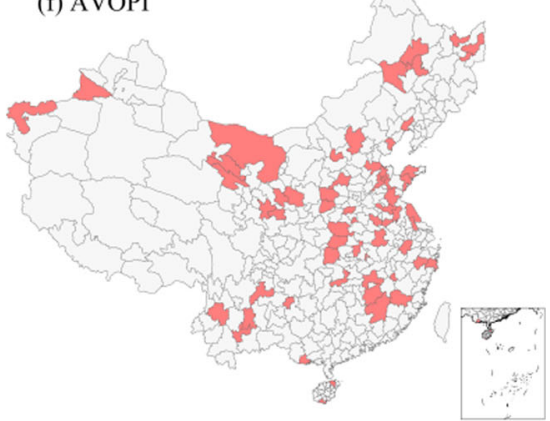

(i) UR

Fig. 9 Spatial distribution of dominant factors at prefectural scale. Please refer to Table 1 for the full names of the driving factors
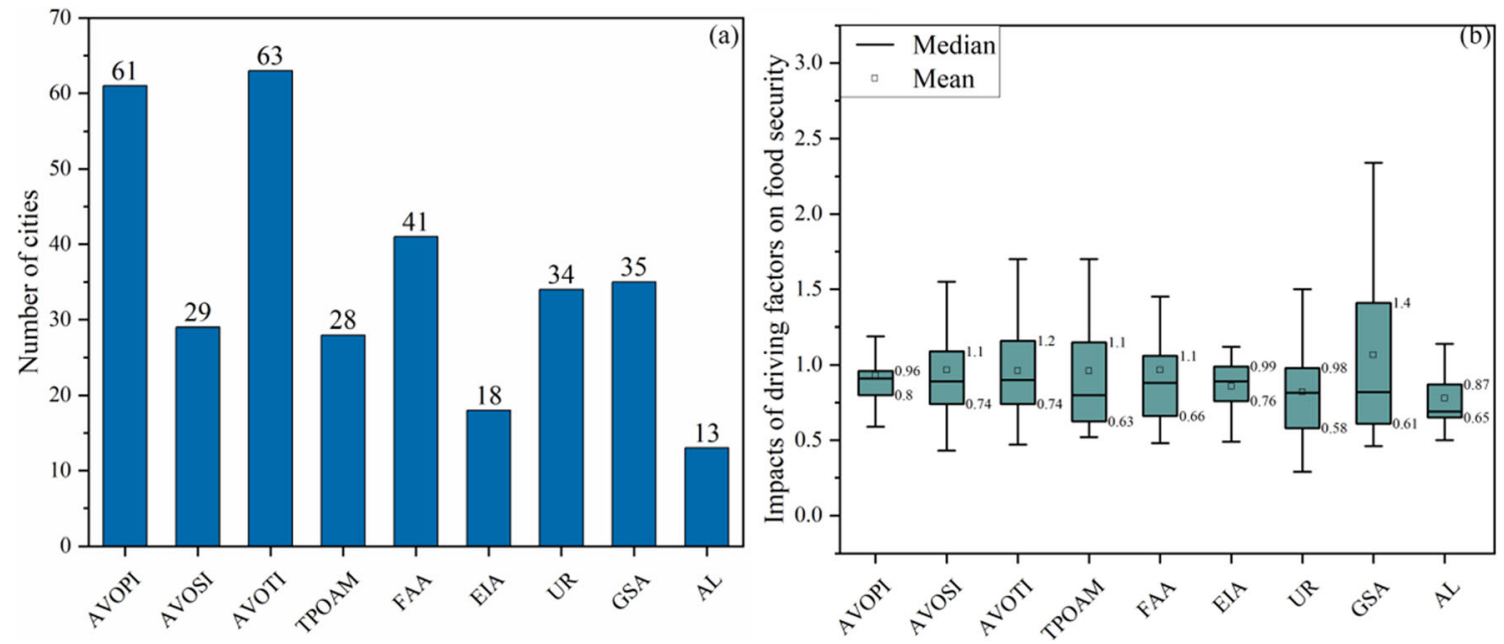

Fig. 10 Number of cities dominated by different driving factors (a) and impacts of driving factors on food security (b). Notes: Please refer to Table 1 for the full names of driving factors 

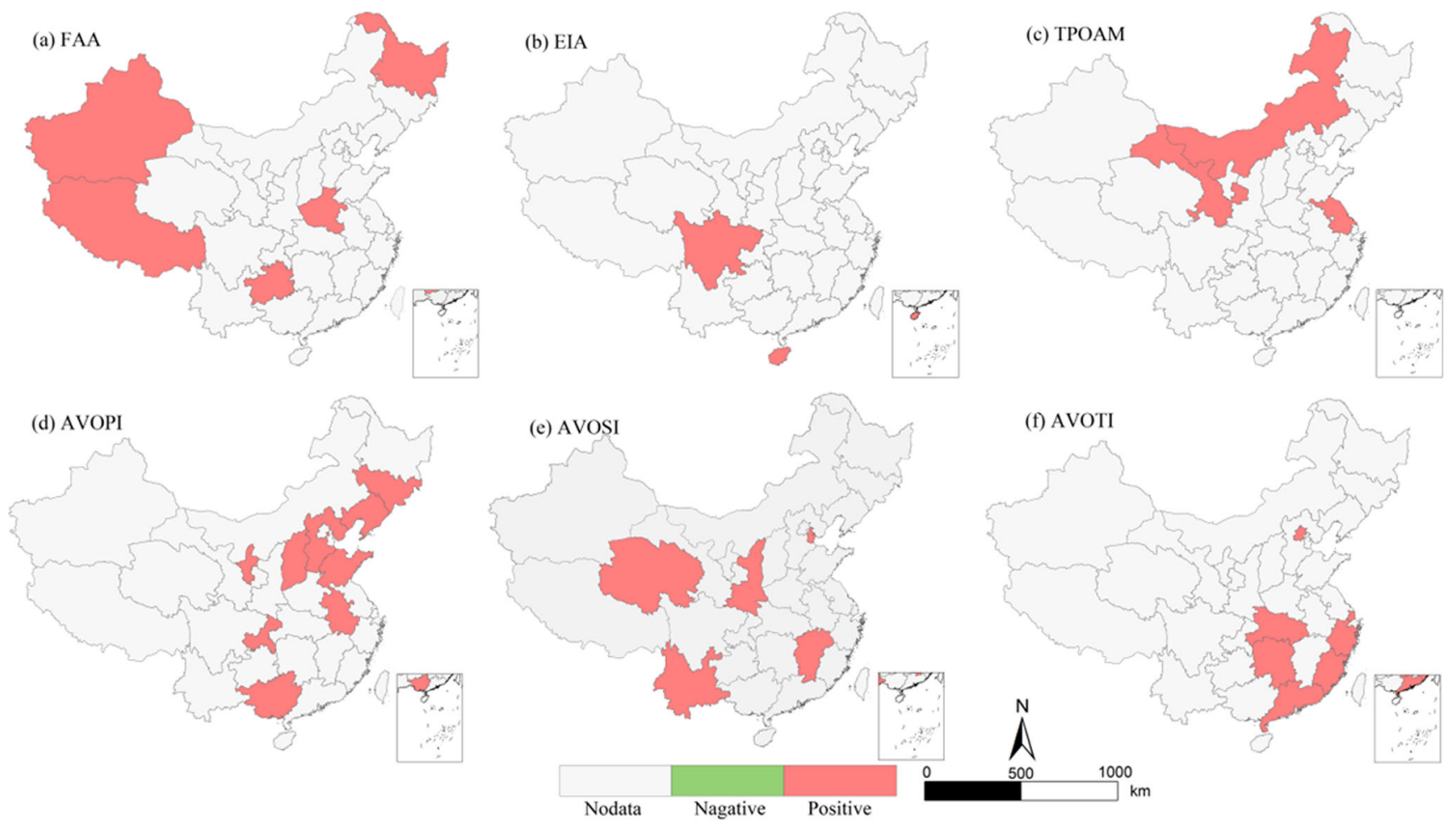

Fig. 11 Spatial distribution of dominant factors at provincial scale. Notes: Please refer to Table 1 for the full names of the driving factors

more than six times during the research period (China's economic and social big data research platform; https://data.cnki. net). Moreover, the region is rich in coal and oil resources and is a hotspot of China's economic growth (Qi et al. 2013). By contrast, food security decreased significantly in the southeast coastal areas; in particular, food security in Wenzhou, Zhejiang Province, dropped from high security (HS) to low security (LS). A possible reason is that the rapid expansion of cities in the southeast coastal areas has occupied a large amount of arable land (Liu et al. 2012; Wang et al. 2018a), leading to a decline in total grain output. From 1980 to 2017, except Wenzhou, the food security of 18 cities in the southeast

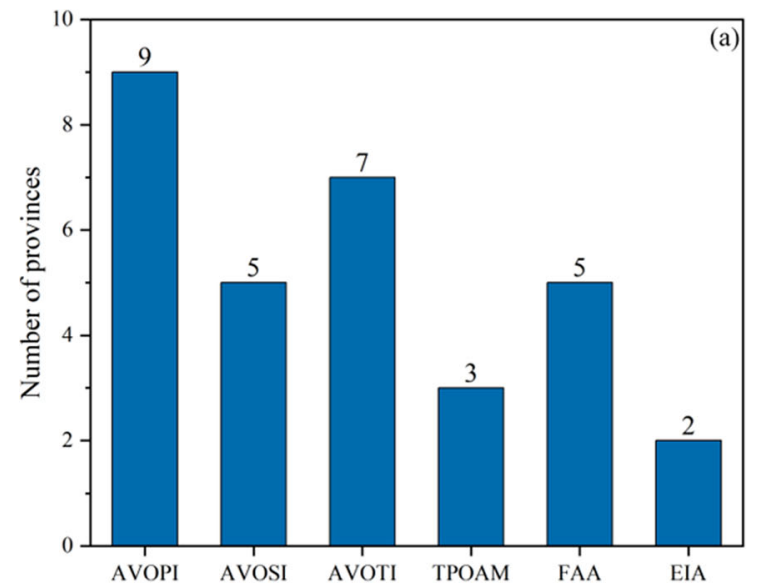

coastal areas showed a downward trend. This suggests that economic development cannot necessarily compensate for the effect of urban expansion on food security caused by the encroachment on cultivated land.

At the provincial level, despite decreasing grain production in Qinghai, Shanghai, Beijing, Fujian, Guangdong, Sichuan, and Zhejiang, food security in those provinces significantly improved as a result of rapid economic growth (Fig. 11). Similar to the food-security pattern at the prefectural level, food-security hotspots at the provincial level were mainly distributed in Northeast China and Inner Mongolia (Fig. 6). The reason for this is that Northeast China is a major grain-

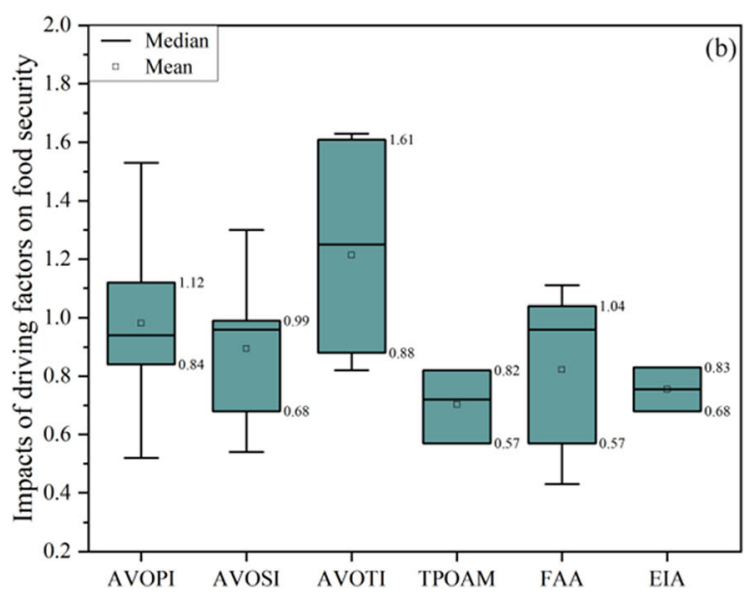

Fig. 12 Number of provinces dominated by different driving factors (a) and impacts of driving factors on food security (b). Notes: Please refer to Table 1 for the full names of the driving factors 
Table 3 Standardized regression coefficients and coefficients of determination $\left(R^{2}\right)$ between driving factors and food security state at provincial scale

\begin{tabular}{|c|c|c|c|c|c|c|c|c|c|c|c|c|}
\hline \multirow[t]{2}{*}{ Province } & \multicolumn{11}{|c|}{ Standardized regression coefficients } & \multirow[t]{2}{*}{$R^{2}$} \\
\hline & AVOPI & AVOSI & AVOTI & UR & GSA & $\mathrm{AL}$ & TPOAM & FAA & EIA & TEM & PRE & \\
\hline Beijing & & & $1.32 * *$ & & $0.43 * *$ & & & & & & & 0.97 \\
\hline Tianjin & & $0.99 * *$ & & & & & & & & & & 0.99 \\
\hline Hebei & $1.12 * *$ & & & $-0.55^{* *}$ & & & & $0.44 * *$ & & & & 0.97 \\
\hline Shanxi & $0.90 * *$ & & & & $0.12 *$ & & & & & & $0.20 * *$ & 0.91 \\
\hline Inner Mongolia & & & & & $0.20 * *$ & & $0.82 * *$ & & & & $0.11^{* *}$ & 0.98 \\
\hline Liaoning & $0.95 * *$ & & & & & & & & & & & 0.90 \\
\hline Jilin & $0.66^{* *}$ & & & $0.34 * *$ & & & & & & & $0.10 *$ & 0.93 \\
\hline Heilongjiang & & & & $-0.4 * *$ & & & & $1.04 * *$ & $0.31 * *$ & & & 0.97 \\
\hline Shanghai & & & $1.25 * *$ & & $0.68 * *$ & & & & & & & 0.93 \\
\hline Jiangsu & & & $0.50 * *$ & & $0.42 * *$ & & $0.72 * *$ & & & & & 0.96 \\
\hline Zhejiang & & & $1.60 * *$ & & $1.34 * *$ & & & & & & & 0.94 \\
\hline Anhui & $1.37 * *$ & & & & & & & & $-0.44 *$ & & & 0.92 \\
\hline Fujian & & & $1.63 * *$ & & $0.86^{* *}$ & & & & & & & 0.96 \\
\hline Jiangxi & & $0.68 * *$ & & $0.27 * *$ & $0.19 * *$ & & & & & & & 0.96 \\
\hline Shandong & $0.84 * *$ & & & & $0.24 * *$ & & & $0.29 * *$ & & & & 0.96 \\
\hline Henan & $0.44^{*}$ & & & & $0.16^{*}$ & & & $0.43 * *$ & & & & 0.69 \\
\hline Hubei & & & $0.88 * *$ & & $0.39 * *$ & & & $0.28 *$ & & & & 0.91 \\
\hline Hunan & & & $0.98 * *$ & & & & & $0.13 * *$ & & & & 0.93 \\
\hline Guangdong & & & $0.82 * *$ & & & & & & & & & 0.67 \\
\hline Guangxi & $1.53 * *$ & & & & $0.82 * *$ & & & & & & & 0.85 \\
\hline Hainan & & & & & & & & & $0.83 * *$ & & & 0.69 \\
\hline Chongqing & $0.94 * *$ & & & & & $-0.18 * *$ & & $0.20 *$ & & & & 0.96 \\
\hline Sichuan & & & & & & & & & $0.68 * *$ & & & 0.45 \\
\hline Guizhou & $0.47 * *$ & & & & & & & $0.57 * *$ & & & $0.13 * *$ & 0.94 \\
\hline Yunnan & & $0.54 * *$ & & & $0.50 * *$ & & & & & & & 0.97 \\
\hline Xizang & & & & & $0.51 * *$ & & & $1.11 * *$ & & $0.24 *$ & $0.16^{*}$ & 0.86 \\
\hline Shaanxi & & $0.96^{* *}$ & & & & & & & & & & 0.91 \\
\hline Gansu & & & $0.43 * *$ & & & & $0.57 * *$ & & & & & 0.95 \\
\hline Qinghai & & $1.30 * *$ & & & $0.72 * *$ & & & & & & & 0.90 \\
\hline Ningxia & $0.52 * *$ & & & & $0.30^{* *}$ & & & & $0.28 * *$ & & & 0.97 \\
\hline Xinjiang & & & & & & & & $0.96 * *$ & & & & 0.91 \\
\hline
\end{tabular}

*The significance at the 0.05 level; ** the significance at the 0.01 level. Please refer to Table 1 for the full names of the driving factors

producing region. In 1980, it accounted for $10 \%$ of China's grain output (China's economic and social big data research platform; http://data.cnki.net/). As a result of the rise of global temperature and the expansion of arable land in this region (Qin et al. 2013; Yang et al. 2007), Northeast China accounted for 21\% of China's grain output in 2017 (China's economic and social big data research platform). In addition to the northeast region, food security also improved rapidly in Inner Mongolia, where the arable land area had increased by more than two million ha since 1980 (Wu et al. 2015). In addition, owing to the development of mining, tourism, and manufacturing, Inner Mongolia's per-capita income increased by 8.5 times from 1987 to 2015 (Shang et al. 2019), greatly increasing food purchasing power and food security. Provinces with low food security were mainly distributed in the central and southwestern regions, which are not major grain-producing areas. Moreover, compared with the eastern regions, in the western provinces, poverty rates were much higher, per-capita GDP was significantly lower (Fleisher et al. 2010; Ye et al. 2014), and grain output and grain purchasing power were relatively low. In 2017, the lowest level of food security was found in Qinghai Province, which is located in the high, cold region of the Qinghai-Tibet Plateau and is not suitable for crops. Consistent with the present 
study's results, Qi et al. (2015) also found that Qinghai Province's food security was at a high level of risk based on an assessment of grain supply and demand.

At the national scale, overall food security in China showed an upward trend from 1980 to 2017; this differs from the results of previous studies. Analyzing food supply and demand, Ye et al. (2013) found that, before 2010, China's food security was on the rise; after 2010 , however, it started to decline as a result of rapid population growth and nonoptimal socioeconomic and agricultural development. There are a couple reasons for these divergent results. First, in the assessment of China's food security, the present study considered not only the food supply but also the supplementary role of economic purchasing power in food shortage. Second, this study considered the state of China's food security relative to the global average level. This is different from Ye et al. (2013), who simulated changes in grain yield under future climate scenarios and assessed the effects on food security.

\section{Mechanisms underlying the effect of major factors on food security}

Clarifying the relationship between food security and its driving factors can help improve regional food security. This study found that climate factors had a relatively small effect on food security compared with human activity (e.g., socioeconomic and agricultural activities).

In the multivariate regression analysis, the main factors affecting food security showed differences in scale. At the prefectural scale, taking Xishuangbanna in Yunnan Province as an example, AVOTI was the main food-security factor. After 1980, the structure of agricultural cultivation in the region changed from grain crops (e.g., rice) to economic crops (e.g., bananas, rubber, and tea) (Nomoto and Yokoyama 2020; Shen et al. 2017), which do not meet the food needs of local people. Additionally, Xishuangbanna is a popular tourist destination. Tertiary industry is the pillar of the local economy, accounting for 54.5\% of the city's GDP (Gao et al. 2019), which can provide food purchasing power and ensure food security for local people. At the provincial level, AVOSI was the main factor affecting food security in Yunnan Province. This is because Yunnan is mainly on a plateau; only $6 \%$ of the land is suitable for agricultural cultivation, the quality of cultivated land is low (Luo et al. 2014), and the grain output accounts for less than 3\% of the national total. However, Yunnan is rich in energy, and its secondary industry, mainly nonferrous metals and hydropower, has developed rapidly, driving local GDP growth and helping to ensure local people's food purchasing power (Deng et al. 2016; Qu et al. 2019). At the national level, AVOPI played a key role in China's food security. Agricultural production has always played an important role in China's economic development and in people's lives (Mukhopadhyay et al. 2018). Since
1978, agriculture has developed rapidly, with the average annual growth rate of gross agricultural product reaching $6.1 \%$ from 1978 to $2015,2.4$ times that of the socialist period (1949-1977) (Gong 2018). This has helped to greatly improve food security in China.

The main factors affecting food security also exhibited spatial heterogeneity. At the prefecture level, Altay in Xinjiang is located in the arid region, with an average annual rainfall of 139.3-268.4 $\mathrm{mm}$ (Fu et al. 2017). Water is the main factor limiting local crop growth, and increasing the irrigated area can significantly improve crop yield (Zhang et al. 2015). Therefore, effective irrigated area (EIA) was the leading factor affecting local food security. By contrast, in Jinchang, Gansu Province, arable land area (AL) was the main factor, while in Hohhot and Inner Mongolia, FAA plays a key role in improving crop yield and food security. At the provincial level, there were also significant differences in the main factors affecting food security. Compared with the national average level, the amount of chemical fertilizer applied in agriculture in Xinjiang Autonomous Region was less. For provinces in East China, the service-dominated tertiary industry developed rapidly, greatly improving local economic development levels. From 1978 to 2010, the per-capita GDP in the coastal areas increased by more than 18 times (He et al. 2014), thus greatly improving food purchasing ability and food security. In some cities, urbanization and other factors had negative effects on food security. For example, urban expansion in Meishan City has occupied a large amount of high-quality arable land resources (Liu et al. 2014), thus reducing the local grain output and food security.

\section{Implications for improving food security}

This study's findings indicated that social, economic, and agricultural management measures can explain food-security changes in China. Multiscale research can therefore provide scientific suggestions for improving food security at various scales. First, with agriculture as a basic industry, focusing on the development of primary industry is key to improving food security. In this regard, the following measures can be taken: (1) Improve the intensive use of urban land, reduce urban sprawl's encroachment on cultivated land, protect the conservation "red line" of 1.8 billion mu of cultivated land, and avoid changing cultivated land to nongrain crops; (2) increase agricultural subsidies, stimulate farmers' enthusiasm for agricultural production, ensure that grain-planting areas do not decrease, and improve China's self-sufficiency in grain production. Second, agricultural management measures should be improved to increase grain production. Specific measures include the following: (1) Improve irrigation infrastructure and methods and adopt appropriate irrigation technologies (e.g., flood, sprinkler, and surface/subsurface drip irrigation) to improve water-resource utilization; (2) Increase investment 
in agricultural machinery to achieve mechanized agricultural production and increase grain output; (3) apply accurate amounts of fertilization based on the characteristics of the crop-growth period to improve fertilization use efficiency. In summary, improving food security requires adjusting policies and measures according to local conditions, in consideration of the main factors affecting local food security.

\section{Conclusions}

This study built a food security index based on the global average to quantify the spatiotemporal patterns of food security in China. The risk areas of food security were identified. The effects of social, economic, agricultural, and climatic factors were analyzed at multiple scales (prefecture, provincial, and country) using multiple stepwise regression. A multiscale approach is needed to quantify food security dynamics and that single perspective methods can misrepresent spatiotemporal variations and key influencing factors.

Food security in China and its influencing factors are characterized by spatial heterogeneity and differences in scale, and smaller scale showed greater heterogeneity than the larger scale; therefore, multiscale research can provide more scientific suggestions for improving food security at various scales. At the prefectural level, food security had obvious spatial heterogeneity, and more than $90 \%$ of cities showed an upward trend in food security, with the most marked improvements occurring in North and Northeast China. Added value of tertiary, which can provide food purchasing power (domestic or international trade) and ensure local food security, was the main factor affecting food security. Moreover, for $89 \%$ of cities, the agricultural factors of arable land area, grain-sown area, and the social factor of urbanization exerted positive effects on food security and had negative effects for $11 \%$ of cities. At the provincial level, food security in all provinces was on the rise during the research period. Hotspots were concentrated in Northeast China while cold spots were concentrated in southern provinces. The gross agricultural output value was the main determinant of food security. At the national scale, food security showed a significant upward trend, and added value of primary was the main influencing factor. The agricultural (fertilizer application amount, effective irrigation area, total power of agricultural machinery) and economic (added value of primary, secondary, and tertiary industry) factors had positive effects on the level of food security at the three scales.

Compared with human activity (social, agricultural, economic), climate change had less impact on food security, and economic factors played predominant role at three scales. Our study is helpful to clarify the spatiotemporal dynamics of China's food security and its driving factors and make effective adjustments to the food security policies at various scales.

Author contribution Writing - original draft; visualization (Furong Lv); formal analysis of the data (Longyun Deng); conceptualization of the research (Zhengtao Zhang); design and development of methodology (Zheye Wang); supervision of the research work (Quanyuan Wu); writing - reviewing and editing; funding acquisition (Jianmin Qiao).

Funding This study was supported by the China Postdoctoral Science Foundation (grant 2018M642691) and the Natural Science Foundation of Shandong Province (grant ZR2020QD011).

Data availability All data generated or analyzed during this study are included in this published article.

\section{Declarations}

Ethics approval and consent to participate All authors carefully read and approved the study.

Consent for publication All authors agreed to publish the manuscript.

Competing interests The authors declare no competing interests.

\section{References}

Andersson Djurfeldt A (2015) Urbanization and linkages to smallholder farming in sub-Saharan Africa: implications for food security. Glob Food Sec 4:1-7

Barrett CB (2010) Measuring food insecurity. Science 327(5967):825828

Cai J, Ma E, Lin J, Liao L, Han Y (2020) Exploring global food security pattern from the perspective of spatio-temporal evolution. J Geogr Sci 30(2):179-196

Cao X, Wu M, Zheng Y, Guo X, Chen D, Wang W (2017) Can China achieve food security through the development of irrigation? Reg Environ Chang 18(2):465-475

Chen J (2007) Rapid urbanization in China: a real challenge to soil protection and food security. Catena 69(1):1-15

Chen Y, Li X, Wang J (2011) Changes and effecting factors of grain production in China. Chin Geogr Sci 21(6):676-684

Conceição P, Levine S, Lipton M, Warren-Rodríguez A (2016) Toward a food secure future: ensuring food security for sustainable human development in Sub-Saharan Africa. Food Policy 60:1-9

Deng M, Li W, Hu Y (2016) Decomposing industrial energy-related CO2 emissions in Yunnan Province, China: switching to low-carbon economic growth. Energies 9(1):23

FAO (1996) Rome declaration on world food security and world food summit plan of action. FAO, Rome

Fleisher B, Li H, Zhao MQ (2010) Human capital, economic growth, and regional inequality in China. J Dev Econ 92(2):215-231

Fu Q, Li B, Hou Y, Bi X, Zhang X (2017) Effects of land use and climate change on ecosystem services in Central Asia's arid regions: a case study in Altay Prefecture, China. Sci Total Environ 607-608:633646

Gao J, Ryan C, Cave J, Zhang C (2019) Tourism border-making: a political economy of China's border tourism. Ann Tour Res 76:1-13 
Godfray HCJ, Beddington JR, Crute IR, Haddad L, Lawrence D, Muir JF, Pretty J, Robinson S, Thomas SM, Toulmin C (2010) Food security: the challenge of feeding 9 billion people. Science 327(5967):812-818

Gong B (2018) Agricultural reforms and production in China: changes in provincial production function and productivity in 1978-2015. J Dev Econ 132:18-31

Grebmer KV, Ringler C, Rosegrant MW, Olofinbiyi T, Wiesmann D, Fritschel H, Badiane O, Torero M, Yohannes Y, Thompson JM (2012) Global hunger index: the challenge of hunger: Ensuring sustainable food security under land, water and energy stresses. International Food Policy Research Institute, pp. 7-9

He Q, Bertness MD, Bruno JF, Li B, Chen G, Coverdale TC, Altieri AH, Bai J, Sun T, Pennings SC (2014) Economic development and coastal ecosystem change in China. Sci Rep 4(1):1-9

Huang J, Yang G (2017) Understanding recent challenges and new food policy in China. Glob Food Sec 12:119-126

Kang S, Hao X, Du T, Tong L, Su X, Lu H, Li X, Huo Z, Li S, Ding R (2017) Improving agricultural water productivity to ensure food security in China under changing environment: from research to practice. Agric Water Manag 179:5-17

Laborde D, Martin W, Swinnen J, Vos R (2020) COVID-19 risks to global food security. Science 369(6503):500-502

Lake IR, Hooper L, Abdelhamid A, Bentham G, Boxall AB, Draper A, Fairweather-Tait S, Hulme M, Hunter PR, Nichols G, Waldron KW (2012) Climate change and food security: health impacts in developed countries. Environ Health Perspect 120(11):1520-1526

Leisner CP (2020) Review: Climate change impacts on food securityfocus on perennial cropping systems and nutritional value. Plant Sci 293:110412

Li H, Zhang X (2017) A spatial explicit assessment of food security in Africa based on simulated crop production and distribution. J Clean Prod 147:628-636

Li M, Singh VP (2019) Sustainability of water and energy use for food production based on optimal allocation of agricultural irrigation water. Int J Water Resourc Dev 36(2-3):528-546

Liu J, Zhang Q, Hu Y (2012) Regional differences of China's urban expansion from late 20th to early 21 st century based on remote sensing information. Chin Geogr Sci 22(1):1-14

Liu J, Kuang W, Zhang Z, Xu X, Qin Y, Ning J, Zhou W, Zhang S, Li R, Yan C, Wu S, Shi X, Jiang N, Yu D, Pan X, Chi W (2014) Spatiotemporal characteristics, patterns, and causes of land-use changes in China since the late 1980s. J Geogr Sci 24(2):195-210

Liu X, Shi L, Engel BA, Sun S, Zhao X, Wu P, Wang Y (2020a) New challenges of food security in Northwest China: water footprint and virtual water perspective. J Clean Prod 245:118939

Liu X, Shi L, Qian H, Sun S, Wu P, Zhao X, Engel BA, Wang Y (2020b) New problems of food security in Northwest China: a sustainability perspective. Land Degrad Dev 31(8):975-989

Luo J, Zhan J, Lin Y, Zhao C (2014) An equilibrium analysis of the land use structure in the Yunnan Province, China. Front Earth Sci 8(3): 393-404

Masters WA, Djurfeldt AA, De Haan C, Hazell P, Jayne T, Jirström M, Reardon T (2013) Urbanization and farm size in Asia and Africa: implications for food security and agricultural research. Global Food Security 2(3):156-165

Merem EC, Twumasi Y, Wesley J, Alsarari M, Fageir S, Crisler M, Romorno C, Olagbegi D, Hines A, Ochai GS, Nwagboso E, Leggett S, Foster D, Purry V, Washington J (2019) Regional assessment of the food security situation in West Africa with GIS. Food Pub Health 9(2):60-77

Molotoks A, Smith P, Dawson TP (2021) Impacts of land use, population, and climate change on global food security. Food Energ Sec 10(1):e261
Mondal S (2020) Modeling the spatial pattern of household quality of living in West Bengal: an approach of hotspot and cluster analysis. Model Earth Syst Environ 6(2):833-851

Mukhopadhyay K, Thomassin PJ, Zhang J (2018) Food security in China at 2050: a global CGE exercise. J Econ Struct 7(1):1

Nath R, Luan Y, Yang W, Yang C, Chen W, Li Q, Cui X (2015) Changes in arable land demand for food in India and China: a potential threat to food security. Sustainability 7(5):5371-5397

Niu Y, Xie G, Xiao Y, Liu J, Wang Y, Luo Q, Zou H, Gan S, Qin K, Huang M (2021) Spatiotemporal patterns and determinants of grain self-sufficiency in China. Foods 10(4),747

Nomoto S, Yokoyama SM (2020) Fog and people in Xishuangbanna, Yunnan Province, China, Nature, Culture, and Food in Monsoon Asia. Springer, pp. 41-53

Pinstrup-Andersen P (2009) Food security: definition and measurement. Food Security 1(1):5-7

Qaim M (2020) Role of New Plant Breeding Technologies for Food Security and Sustainable Agricultural Development. Appl Econ Perspect Policy 42(2):129-150

Qi X, Vitousek PM, Liu L (2015) Provincial food security in China: a quantitative risk assessment based on local food supply and demand trends. Food Security 7(3):621-632

Qi Y, Yang Y, Jin F (2013) China's economic development stage and its spatio-temporal evolution: a prefectural-level analysis. J Geogr Sci 23(2):297-314

Qin Y, Liu J, Shi W, Tao F, Yan H (2013) Spatial-temporal changes of cropland and climate potential productivity in northern China during 1990-2010. Food Security 5(4):499-512

Qu Q, Wang L, Cao Z, Zhong S, Mou C, Sun Y, Xiong C (2019) Unfolding the price effects of non-ferrous industry chain on economic development: a case study of Yunnan province. Res Policy 61:1-20

Shang C, Wu T, Huang G, Wu J (2019) Weak sustainability is not sustainable: socioeconomic and environmental assessment of Inner Mongolia for the past three decades. Resour Conserv Recycl 141: 243-252

Shen S, Xu G, Li D, Clements DR, Zhang F, Jin G, Wu J, Wei P, Lin S, Xue D (2017) Agrobiodiversity and in situ conservation in ethnic minority communities of Xishuangbanna in Yunnan Province, Southwest China. J Ethnobiol Ethnomed 13(1):28

Sisha TA (2020) Household level food insecurity assessment: evidence from panel data, Ethiopia. Scientific African 7:e00262

Tao F, Yokozawa M, Liu J, Zhang Z (2008) Climate change, land use change, and China's food security in the twenty-first century: an integrated perspective. Clim Chang 93(3-4):433-445

United Nations (UN) (2015) Transforming Our World: The 2030 Agenda for Sustainable Development. Seventieth Session of the United Nations General Assembly Resolution A/RES/70/1. (UN, New York).

Wang J, Zhang Z, Liu Y (2018a) Spatial shifts in grain production increases in China and implications for food security. Land Use Policy 74:204-213

Wang M, Ma L, Strokal M, Chu Y, Kroeze C (2018b) Exploring nutrient management options to increase nitrogen and phosphorus use efficiencies in food production of China. Agric Syst 163:58-72

Wang Y-S (2019) The challenges and strategies of food security under rapid urbanization in China. Sustainability 11(2):542

Wei X, Zhang Z, Shi P, Wang P, Chen Y, Song X, Tao F (2015) Is yield increase sufficient to achieve food security in China? PLoS One 10(2):e0116430

Wei X, Zhang Z, Wang P, Tao F (2017) Recent patterns of production for the main cereal grains: implications for food security in China. Reg Environ Chang 17(1):105-116

Wu J, Zhang J, Wang S, Kong F (2016) Assessment of food security in China: a new perspective based on production-consumption coordination. Sustainability 8(3):183 
Wu J, Zhang Q, Li A, Liang C (2015) Historical landscape dynamics of Inner Mongolia: patterns, drivers, and impacts. Landsc Ecol 30(9): 1579-1598

Wu W, Tang H, Yang P, You L, Zhou Q, Chen Z, Shibasaki R (2011) Scenario-based assessment of future food security. J Geogr Sci 21(1):3-17

Yang X, Lin E, Ma S, Ju H, Guo L, Xiong W, Li Y, Xu Y (2007) Adaptation of agriculture to warming in Northeast China. Clim Chang 84(1):45-58

Ye L, Tang H, Wu W, Yang P, Nelson GC, Mason-D'Croz D, Palazzo A (2014) Chinese food security and climate change: agriculture futures. Economics 8(2014-1):1-39

Ye L, Xiong W, Li Z, Yang P, Wu W, Yang G, Fu Y, Zou J, Chen Z, Van Ranst E, Tang H (2013) Climate change impact on China food security in 2050. Agron Sustain Dev 33(2):363-374
Yu D, Qiao J, Shi P (2018) Spatiotemporal patterns, relationships, and drivers of China's agricultural ecosystem services from 1980 to 2010: a multiscale analysis. Landsc Ecol 33(4):575-595

Zhang Q, Sun P, Li J, Singh VP, Liu J (2015) Spatiotemporal properties of droughts and related impacts on agriculture in Xinjiang, China. Int J Climatol 35(7):1254-1266

Zurayk R (2020) Pandemic and food security: a view from the global south. J Agric Food Syst Commun Dev 9(3):1-5

Publisher's note Springer Nature remains neutral with regard to jurisdictional claims in published maps and institutional affiliations. 